\title{
TWO CASES OF WOUNDS OF THE FEMALE GEXITALS.
}

\author{
By R. J. KINKEAD, M.D., Dub. ; \\ Professor of Obstetrics; Queen's College, Galway; \\ Physician and Gynæcologist to the Galway Hospital. \\ [Read in the Section of Obstetrics, March 10, 1905.]
}

WHex a woman falls astride on a hard substance, or receives a kick on the genitals, owing to the small amount of tissue between the surface and the bones, the resulting wound is incised rather than Jacerated. The vulva being profusely supplied with blood-ressels, and the veins forming the bulbs of the vagina anastomosing freely with those of the vagina, uterus, and rectum, the bleeding from such wounds is profuse, and if the woman be pregnant is apalling; the nearer to term the larger the ressels, and the greater and more rapid the loss of blood. In all cases dangerous, in advanced pregnancy wounds of the genitals are usually fatal. We not infrequently read in the papers a report that a pregnant woman received a kick in the lower part of her body, was immediately conveyed to hospital, and was either found to be dead on arrival, or died in a few minutes after admission.

The two following cases are interesting, one from a forensic as well as from a surgical point of view; the other from the extensive injuries inflicted:-

About 7 p.m. one evening in the Spring of 1903, I was stopped on my way home and asked to go at once to a woman who had met with an accident, and was "bleeding to death." Her husband, who gave me the message, said he had rushed off at once, it took me two minutes to ride to the house, so I saw her 


\section{Two Cases of Wounds of the Female Genitals.}

within ten minutes of her being wounded. She was a married woman, aged thirty-four, the mother of several children, and some months previously had had a bad miscarriage. I found her blanched, pulseless, the heart's sounds almost inaudible, sightless, semiconscious, respiration sighing. There being no visible wound, a trained maternity nurse, who had gone to her assistance, believed the bleeding to be uterine, and had applied wet cloths to the vulva and lower parts of the abdomen; the bleeding had ceased, but the woman was perilously near death. I gave her a hypodermic of ether, had hot bottles applied to feet, limbs and body; some ounces of hot normal saline were thrown up the rectum, and ten ounces transfused under the breasts. As she rallied the bleeding recommenced from a wound in the anterior wall. She was too weak and collapsed for operative interference, so I had to be content with plugging and the application of a " $\mathrm{T}$ " bandage.

In the morning, April 24th, there having been no further hæmorrhage, she was brought to hospital. I found an apparently incised transverse wound, an inch and a half in length, in the anterior vaginal wall, fully an inch inside orifice, involving the urethra, and which bled freely on removal of plugs. To stop the bleeding, rather than in the hope of obtaining union, I sutured it. Her temperature on admission was $90^{\circ}$, at night $101^{\circ}$. On the 25 th there was no bleeding, temperature $100^{\circ}$ to $101^{\circ}$, vomiting during night; some oozing on the 26th, which was stopped by adrenalin; wound not looking healthy. Vomiting continued on the 29th ; right wrist became painful and puffy; edges of wound sloughing; touched with pure carbolic acid.

She went through a severe attack of septicæmia, in addition to the right wrist the right groin and left shoulder were affected, constant vomiting, profuse sweating. On three occasions the temperature went up to $105.8^{\circ}$ and $105.6^{\circ}$, but fell immediately on administration of Warburg's tincture. She was discharged on July 27th. The application of carbolic acid stopped sloughing of wound, which, however, was slow in healing. Although the urethra was cut, and for a considerable time urine escaped through the wound, there is now, after the lapse of over a year, no stricture, nor any difficulty in micturition.

Her history of the occurrence was that she had a dispute with 
her husband, that he gave her a push; she had stumbled and fallen over a Windsor chair, the legs of which had been cut down for nursing purposes, and that one of the legs had gone up into her. After her recovery, however, she admitted that the injury was produced by a kick, the story of the overturned chair being invented to shield her husband.

It is here that the medico-legal interest of the case comes in, for the appearance was consistent with the chair story, as there was no injury of the vulva, the only external mark being an ecchymosis, which appeared on the second day, half-way between the right labium majus and the thigh, while, à priori, it was to be expected that the toe of a labourer's boot was bound to have injured the external genitals, and that it could not possibly have inflicted a wound inside the vagina either with or without damage to the vulva. The explanation seems to be that in this case, as in a number of multipara, there was a slight prolapse of the anterior vaginal wall, which caused the lower inch, or inch and half of the anterior column to protrude through the vaginal orifice, when the woman was standing up. A kick, when in the erect position, with the legs separated, if it took effect in the middle line, would drive the protruded portion against the pubic arch, cutting it like a knife. The patient being examined lying down, the wound would be found inside the vagina, and the inference would be that it must have been inflicted by some instrument introduced within that canal.

In the second case the injury was the result of accident.

A servant girl, putting up window curtains, doing what she was warned not to do, stood on the flat top of a step-ladder. She slipped and fell straddlelegs, the corner of the flat top of the ladder evidently struck her inside the right labium majus. 


\section{Two Cases of Wounds of the Female Genitals.}

The bleeding was severe, but not excessive. She was brought into town, and I was sent for to see her. A cursory examination showed grave injury, and I had her at once removed to the Galway Hospital. Though she had lost much blood she was not collapsed, and was at once put under ether. The wound and genitals were thoroughly irrigated and cleansed. I found a wound extending from a little below the level of the posterior margin of the vaginal orifice, on the right side of, and within, the vulva, to the level of the pubic arch; its depth at the lower angle was an inch, getting deeper as it passed up, till it attained a depth of quite three inches at its upper angle; nor was this all, for it penetrated under the tissues, and on passing my finger up, I found the pubes laid bare up to the middle margin of the symphysis. The urethra had been torn from its attachments and pushed downwards and over to the left side. The vagina was also displaced and the hymeneal attachment above, to the right and about half way below, torn from the vagina. The hymen was a very perfect one, with a small oval central opening, and could be lifted up, like the lid of the nest of the tarantula spider. I first sutured the deep portion of the laceration under the pubis; I next passed a deep suture along the side of the urethra and out at the upper angle of the wound; another at the anterior margin of the urethra emerging in the vestibule thus bringing it back to, and fixing it in its normal position; and a lateral suture, immediately below the urethra, brought the edges of the wound into apposition to the level of the vaginal orifice. A few fine sutures were then introduced attaching the separated hymeneal margin to its position below the urethra, and at the side; a couple of sutures through the margin of the hymen, along the separated portion of the vagina, under the bottom of the wound, and emerging at the end of the tear, closed the wound, and brought the vagina back to position. The wound was kept constantly irrigated during the stitching, and a catheter was tied in for the first twenty-four hours. Except that the patient was rather collapsed, and vomited a good deal for twenty-four hours, there was no trouble, the wound healed without any suppuration; there was no rise of temperature, the hymen united at the torn margins; and when she left the hospital it needed a close examination to detect any trace of injury. 
The restoration of the hymen may possibly be regarded as trivial, but I believe that when dealing with unmarried women we are bound, if possible, to restore the parts to the condition they were in before accident or operation. I was induced to expend some time and care in suturing the hymen to its severed attachments from my experience in another case, with a very well developed hymen, in which, when operating for stenosis of the cervix, I incised the hymen on both sides, making a posterior flap, that, after completing the operation, I replaced, suturing the cut edges. Union was perfect, not even a nick in the circumference of the aperture marking where the hymen had been cut. 